\title{
TRANSIÇÃO PARA O EXERCÍCIO PROFISSIONAL EM ENFERMAGEM: UMA EXPERIÊNCIA EM GRUPO OPERATIVO
}

\author{
Transition to the professional exercise in nursing: \\ an experience in surgical group \\ Transición para el ejercicio profesional en enfermería: \\ una experiencia en grupo operativo
}

\section{Resumo}

Este estudo qualitativo tem como proposta analisar a utilização da abordagem de grupo operativo de Pichon-Rivière como possibilidade de criar espaço para troca de experiências entre alunos do $8^{\circ}$ semestre do Curso de Graduação em Enfermagem da Escola de Enfermagem de Ribeirão Preto/USP, com o intuito de aliviar ansiedades, facilitando a elaboração das vivências cotidianas, integrando pensar, sentir e fazer. Foram propostos sete encontros grupais, semanalmente, utilizando a técnica de grupo operativo. Os registros foram analisados, sendo construída a crônica de cada encontro. Os discentes refletiram sobre suas vivências no enfrentamento desse momento de transição para a vida profissional e os docentes questionaram as experiências relacionadas ao processo ensino-aprendizagem, repensando acerca dos limites do modelo tradicional de ensino.

Palavras-chave: Enfermagem. Prática Profissional. Ensino. Estudantes de Enfermagem.

\begin{abstract}
This qualitative study aims to analyze the use of PichonRivière's operative group approach, as a possibility for creating a room for the exchange of experiences between students in the $8^{\text {th }}$ term of the Undergraduate Course in Nursing at the University of São Paulo at Ribeirão Preto College of Nursing, with a view to mitigating anxiety, facilitating the elaboration of daily experiences and integrating thoughts, feelings and actions. Seven group meetings were proposed on a weekly basis, using the operative group technique. Records were analyzed and an account was constructed about each meeting. Students reflected on their experiences in facing this moment of transition towards professional life, while lecturers questioned the experiences related to the teaching-learning process, reconsidering the limits of the traditional teaching model.
\end{abstract}

Keywords:

Nursing. Professional Practice. Teaching.

Students of Nursing.

\section{Resumen}

El objetivo de este estudio cualitativo es lo de analizar el uso de la aproximación de grupo operativo de Pichon-Rivière, como posibilidad de crear un espacio para el cambio de experiencias entre alumnos del $8^{\circ}$ semestre del Curso Pregrado en Enfermería de la Escuela de Enfermería de Ribeirão Preto de la Universidad de São Paulo - Brasil, con la finalidad de aliviar ansiedades, facilitando la elaboración de las experiencias cotidianas, integrando pensar, sentir y hacer. Se propusieron siete encuentros grupales, semanalmente, utilizando la técnica de grupo operativo. Los registros fueron analizados y se construyó el relato de cada encuentro. Los alumnos reflexionaron acerca de sus experiencias al enfrentarse con ese momento de transición a la vida profesional y los docentes cuestionaron las experiencias relacionadas al proceso enseñanzaaprendizaje, repensando acerca de los límites del modelo tradicional de enseñanza.

Palabras clave:

Enfermería. Práctica Profesional. Enseñanza.

Estudiantes de Enfermería. 


\section{INTRODUÇÃO}

Ao longo do seu processo de formação, o discente vivencia dificuldades variadas em sua aproximação ao fazer profissional: dúvidas em relação à sua própria escolha, à inserção no cotidiano universitário, às primeiras experiências nos campos de estágios, deparando-se com situações dolorosas como os limites vida-morte e as problemáticas sociais enfrentadas por usuários e trabalhadores nos serviços de saúde, os conflitos vividos com os docentes e entre os próprios alunos, o exercício do papel profissional do enfermeiro em relação com os demais profissionais, as condições do mercado de trabalho, as divergências teórico-práticas. Enfim, algumas incertezas e inseguranças vão conformando-se no decorrer do curso de graduação.

Compreendemos que os discentes vivenciam um momento de mudanças, necessitando de um espaço para a troca e elaboração de experiências, com a intenção de aliviar ansiedades e facilitar o enfrentamento do futuro.

Pensamos que a criação desse espaço deveria fundamentar-se em uma perspectiva que contemplasse a possibilidade dos alunos constituírem seus caminhos, desenvolvendo sua capacidade de crítica, diálogo e compreensão, bem como a criatividade e sensibilidade, primordiais para o processo contínuo de amadurecimento pessoal e grupal.

Desenvolver essa capacidade é relevante tendo em vista as atuais diretrizes curriculares nacionais dos cursos de graduação ${ }^{1}$ que apontam para a valorização do trabalho em grupo e das dimensões políticas, éticas e humanísticas, possibilitando ao aluno a construção de atitudes e valores voltados à cidadania e solidariedade.

Ao mesmo tempo que essas questões vêm nos inquietando, tivemos a oportunidade de realizar o "Curso de Formação de Coordenador de Grupo Operativo" do Instituto de Psicologia Social Enrique Pichon-Rivière de Ribeirão Preto, baseado no referencial teórico da Psicologia Social de Pichon-Rivière. 0 Curso nos proporcionou a oportunidade de vivenciar as relações grupais como instrumento para a aprendizagem cotidiana, envolvendo não somente a aquisição de informações ou elaborações teóricas, mas a possibilidade de rever e refazer vínculos, estabelecendo uma relação dialética com o mundo, na qual a ação transformadora revela-se fundamental.

A partir do referencial Pichoniano, começamos a pensar que ele poderia nos orientar para a realização de atividades que propiciassem a troca e a elaboração de experiências entre os alunos, considerando a problemática acima apresentada. Fomos, assim, instigadas a elaborar este estudo cuja proposta é: analisar a utilização da abordagem de grupo operativo, proposta por
Pichon-Rivière, como possibilidade de criar um espaço para a troca de experiências entre os discentes do $8^{\circ}$ semestre do Curso de Graduação em Enfermagem da Escola de Enfermagem de Ribeirão Preto - Universidade de São Paulo (EERP/USP), com o intuito de aliviar ansiedades e facilitar a elaboração das vivências cotidianas, integrando o pensar, o sentir e o fazer.

Cabe ressaltar que alguns estudos na área de enfermagem já vêm se utilizando do referencial do grupo operativo no ensino e na assistência ${ }^{2-7}$.

\section{A PSICOLOGIA SOCIAL DE PICHON-RIVIÈRE: APROXIMAÇÃO TEÓRICA}

Para Pichon-Rivière ${ }^{8}$, o grupo operativo é um conjunto de pessoas ligadas entre si por constantes de tempo e espaço e articuladas por sua mútua representação interna, propondo explícita e implicitamente uma tarefa, que constitui sua finalidade. No grupo, os participantes interatuam através de mecanismos de assunção e adjudicação de papéis.

Operar é criar condições para que os integrantes promovam uma modificação criativa e uma adaptação ativa à realidade, o que significa compreender o grupo como instrumento a serviço da aprendizagem.

Aprender em grupo significa preocupar-se, não somente com o produto da aprendizagem mas também, com o processo que possibilita a mudança dos sujeitos para a vida?.

0 trabalho em grupo operativo tem a intenção de levar a pessoa a aprender a pensar, ou seja, reaprender a pensar, transformando uma modalidade de pensamento, a dilemática, em outra, a dialética ${ }^{10}$.

0 pensamento dilemático manifesta-se como um estancamento da possibilidade de aprendizagem, criatividade e transformação da realidade, considerando que distorce a leitura da realidade.

A leitura distorcida da realidade significa fragmentar o objeto de conhecimento em partes e também dissociálo de outros objetos, do contexto, conseqüentemente produzindo internamente uma fragmentação do vínculo e do "eu". Por outro lado, o pensamento dialético busca integrar o objeto, compreendendo-o em seu constante movimento, sempre articulado a outros objetos e ao contexto, em uma situação histórica concreta.

Reaprender a pensar, a partir do pensamento dialético, está relacionado à busca de uma visão mais reflexiva da vida cotidiana. Os fatos e os fenômenos do cotidiano apresentam-se, muitas vezes, como algo que não questionamos ou problematizamos, como se já constituíssem o real por excelência. Assim, o cotidiano acaba encoberto, distorcido: esse encobrimento e essa distorção acontecem por meio de um mecanismo peculiar, característico da ideologia dominante, que naturaliza o social, universaliza o particular e 
torna atemporal o que é histórico. Desde esse processo mistificador a vida cotidiana constitui uma ordem natural, universal, eterna e não-modificável ${ }^{11}$.

A técnica de grupo operativo está centrada na tarefa explícita, que consiste em reelaborar o conteúdo (informação/objeto de conhecimento),tendo em vista a proposta de trabalho grupal; e na tarefa implícita que envolve lidar com as ansiedades que representam as resistências às mudanças.

Quando as pessoas operam em grupo, com o objetivo de cumprir a tarefa, atuam através da atribuição e assunção de papéis.

Para Pichon-Rivière o conceito de papel significa um modelo organizado de conduta, relativo a uma certa posição do indivíduo em uma rede de interação, ligado à suas expectativas e de outros ${ }^{12}$.

Nos grupos, podem emergir os seguintes papéis: Porta-voz, Bode Expiatório, Líder e Sabotador. Os papéis não são fixos, mas funcionais e rotativos ${ }^{8}$.

A análise da dinâmica grupal é realizada a partir dos seguintes vetores: afiliação/pertença, cooperação, pertinência, comunicação, aprendizagem ${ }^{13,14}$.

\section{CAMINHAR METODOLÓGICO}

Em uma primeira aproximação, enviamos correspondência a todos os alunos matriculados no $8^{\circ}$ semestre do Curso de Graduação em Enfermagem da EERP/USP, explicitando a nossa proposta de formar um grupo, para proporcionar um espaço para a expressão vivencial dos estudantes no que se refere às ansiedades sentidas no momento de final de curso, utilizando a abordagem de grupo operativo. Estabelecemos o número de encontros, o período, dia da semana e horário de realização (com possibilidade de negociação) e o local para as vivências. Solicitamos que os interessados entrassem em contato com uma das responsáveis para eventuais esclarecimentos.

Participaram dos grupos operativos sete alunos, cabendo esclarecer que, ao longo dos encontros, alguns ausentaram-se, principalmente por dificuldades em conciliar o horário com o estágio supervisionado.

Foram propostos sete encontros semanais, no período de 15 de outubro a 03 de dezembro de 2001, às segunda-feiras, das 17:00 às 18:30 horas, na EERP/USP.

No encontro inicial, os próprios alunos deram sugestões de temas de interesse para serem abordados pelo grupo: "transição aluno-enfermeiro", "perspectivas futuras" e "competição", cabendo salientar que, à medida em que os encontros transcorriam, tanto os docentes como os alunos tinham a liberdade de rediscutir os temas propostos e também sugerir outros. Assim, os docentes, após análise do primeiro grupo operativo, senti- ram necessidade de introduzir a temática "ser enfermeiro", o que foi aceito pelo grupo de alunos. Em um dos últimos encontros, os discentes sugeriram que fosse enfocado o tema "funcionamento dos grupos".

Esses temas foram trabalhados em cada encontro do seguinte modo: inicialmente, era realizado um aquecimento inespecífico envolvendo atividades de aquecimento corporal e, em seguida, algumas atividades como jogos, desenhos e outras que funcionassem como disparador temático para o grupo operativo, ou seja, que mobilizassem os pensamentos e sentimentos dos discentes em relação ao tema a ser enfocado no encontro. As duas atividades (aquecimento inespećifico e disparador temático) tiveram duração de cerca de 30 minutos. Finalmente, era realizado o grupo operativo, com duração em torno de uma hora.

No grupo operativo, um dos docentes fazia a coordenação e os outros dois eram os observadores (o que se manteve fixo em todos os encontros para melhor condução do processo), conforme a abordagem utilizada. Ao iniciá-lo, o coordenador fazia referência ao "enquadre" para o trabalho grupal: tempo de duração, tarefa proposta, enfocando sempre que dois docentes fariam a observação, atuando como membros silentes que se dedicam a fazer os registros da comunicação processada no encontro, o que é fundamental para a compreensão da dinâmica grupal. No último encontro, os alunos fizeram a avaliação final das atividades desenvolvidas.

Os participantes foram consultados quanto à possibilidade de utilização do material registrado para fins de pesquisa. Todos concordaram, assinando o Termo de Consentimento Livre e Esclarecido. 0 estudo foi analisado e aprovado pelo Comitê de Ética em Pesquisa da EERP/USP.

Cabe ressaltar que essa atividade e a posterior análise do estudo foram supervisionadas por duas profissionais com formação na Psicologia Social de Pichon-Rivière.

Assim trata-se de uma pesqui

sa qualitativa. Os registros foram analisados, sendo construída a crônica de cada encontro, ou seja, a síntese do movimento e fenômenos ocorridos durante a reunião, envolvendo também a percepção do coordenador e dos observadores em relação à tarefa grupal, tendo como referência os pontos propostos pelo Instituto de Psicologia Social "Enrique Pichon-Rivière" de Ribeirão Preto (Em Anexo).

Esclarecemos que no primeiro e no último encontro não foram realizadas crônicas porque, neles não foi utilizada a técnica de grupo operativo. No primeiro encontro, os alunos levantaram temas a serem discutidos nos próximos e no último, houve a avaliação do grupo conforme já descrito.

A partir dessa análise, foi possivel avaliar a possibilidade da utilização da abordagem de grupo operativo com os 
alunos do $8^{\circ}$ semestre do Curso de Graduação em Enfermagem, na transição para 0 exercício profissional.

Inicialmente, apresentamos a crônica de cada encontro e, em seguida, a análise geral, conforme proposta deste estudo.

\section{PROCESSO DE CONDUÇÃO DO GRUPO OPERATIVO: AS CRÔNICAS}

\section{Crônica 1: Tema - Transição aluno/profissional}

No início do Grupo Operativo, os alunos mostraram a ansiedade sentida em relação à transição aluno/profissional, comparando esse momento com outras fases de transição já vividas. Porém, consideraram esse período o mais difíicil, tendo em vista as incertezas em relação às escolhas que precisam fazer, o que gera conflitos como ficar/sair/voltar para casa, trabalhar/estudar, estar empregado/desempregado, ter/não ter conhecimento suficiente para dar conta da prática profissional, desejo de autonomia/medo de assumir responsabilidade.

0 tema emergente foi a atuação profissional do enfermeiro, que tem suscitado questionamentos, dúvidas, conflitos e até, desconhecimento em relação ao exerćíio cotidiano.

Ao discutirem a temática emergente, percebemos que os alunos depositavam nos profissionais das instituições nas quais estagiavam, as deficiências do exercício profissional, não falando a respeito de suas próprias dificuldades, ao mesmo tempo que apontavam falhas no processo de formação.

Em relação aos vetores, consideramos que houve pertença, cooperação, pertinência, comunicação e aprendizagem. 0 grupo cumpriu a tarefa, considerando que permaneceu na discussão do tema proposto. 0 tema mobilizou a participação ativa dos alunos, através de uma comunicação predominantemente verbal, com falas complementares e poucos momentos de silêncio. Houve coerência entre abertura e fechamento, pois os alunos iniciaram as suas falas com as preocupações já citadas, mas, no final, conseguiram apontar algumas estratégias que poderiam permitir uma atuação profissional mais segura, fundamentada em conhecimentos e em uma postura crítica e ética.

\section{Crônica 2: Tema - Ser enfermeiro}

Na situação de abertura, os estudantes falaram sobre uma visão idealizada do enfermeiro, mas referiram que não encontraram esse profissional "ideal" na prática, na qual predomina 0 apego às rotinas. Isso gera conflitos em relação ao ser enfermeiro, refletindo a divergência da teoria com a prática, uma vez que 0 aluno não encontra "o modelo" profissional nos campos de estágios.
Nesse encontro, os vetores predominantes foram pertinência, comunicação, cooperação e aprendizagem.

Os alunos permaneceram na tarefa explíita, apesar da temática ter sido abordada com dificuldade, predominando a dimensão conceitual. Essa dificuldade foi evidenciada através de expressões de dúvidas, frustrações, medo de decepção e da responsabilidade em relação a ser enfermeiro.

A comunicação foi permeada por longos silêncios, sendo necessário que o coordenador fizesse várias intervenções.

No decorrer do encontro, os discentes verbalizaram que buscavam fazer uma prática diferenciada em relação aos outros enfermeiros que atuavam na instituição de estágio, valorizando as ações de cuidar que levam em conta a integralidade da pessoa, a importância da escuta e a melhora da qualidade de vida. Assim, apesar da divergência teoria/ prática, eles tentavam fazer com que o campo de estágio fosse um espaço de aprendizagem e, ao mesmo tempo, lidavam com o conflito que essa divergência desperta.

Cabe ressaltar que na realização desse grupo tivemos algumas dificuldades, como o número limitado de participantes, o silêncio constante de um dos membros, assumindo o papel de sabotador, um aluno e um observador compareceram pela primeira vez, além da dificuldade de se trabalhar o tema.

\section{Crônica 3: Tema - Perspectivas futuras}

Os alunos iniciaram suas falas relatando desejos futuros: ter emprego, salário, realização profissional e pessoal. Parte da discussão envolveu as incertezas quanto ao sair/ficar/voltar para casa, trabalhar/estudar, estar empregado/desempregado, criando um clima de ansiedade.

Compreendemos que, como tentativa de enfrentamento dessas incertezas, os participantes passaram a se referir ao futuro mais próximo e concreto, como a elaboração de currículo para concursos e os preparativos para a formatura, sendo este último 0 tema com que finalizaram o encontro.

No decorrer do grupo, as falas apontaram algumas fantasias relacionadas com o futuro, como não conseguir emprego, voltar para casa é ruim, três meses é um prazo tolerável para se reorganizar a vida.

Em relação aos vetores, percebemos a pertença, pertinência, cooperação, comunicação. Os participantes permaneceram na tarefa, abordando a temática de maneira mais vivencial. A comunicação foi predominantemente verbal, com a participação de todos, com breves momentos de silêncios e falas complementares.

Tendo em vista que os sentimentos verbalizados na abertura não foram retomados, de modo reelaborado, no fechamento desse encontro, consideramos que 0 vetor aprendizagem não foi predominante. 


\section{Crônica 4: Tema - Competição}

Os integrantes iniciaram suas falas expondo os sentimentos vividos durante o exerć́cio "o guia e o cego", realizado no aquecimento espećfico. Comentaram que sentiram insegurança por desconhecerem as intenções do outro, relacionando esse sentimento ao tema proposto.

0 grupo demorou certo tempo para fazer uma incursão à temática vivenciada em seu contexto de aluno do $4^{\circ}$ ano, revelando que sentiam dificuldades para falar sobre a competição. Assim, enfocaram novamente algumas perspectivas futuras, com ênfase na festa de formatura.

Posteriormente, os alunos retomaram a discussão sobre o tema proposto desenvolvendo a tarefa explíita, ou seja, fizeram um movimento de aproximação à temática.

Emergiram pólos contraditórios em relação à compreensão da competição: "competição saudável/ competição patológica"; "experiência dolorosa/ experiência motivadora". Porém, cada integrante permaneceu em sua própria posição quanto ao tema, não reelaborando a sua compreensão em conjunto com os demais.

Em relação aos vetores predominantes, observamos a afiliação, pertença, cooperação, pertinência e comunicação. Os participantes permaneceram em tarefa explícita, comunicando-se verbalmente, com falas complementares e poucos momentos de silêncio.

No final do encontro, os discentes fizeram questionamentos sobre 0 trabalho grupal que estavam vivenciando, gerando, assim, a temática para a próxima reunião: "o funcionamento grupal".

\section{Crônica 5: Tema - Funcionamento Grupal}

Os alunos exigiram do coordenador um posicionamento, isto é, um direcionamento mais definido da coordenação. Além disso, questionaram os papéis do coordenador e do observador: por que observar/ não falar/não dar respostas?

Os integrantes, ao fazerem referência sobre o que é grupo operativo, trazem como exemplos situações vivenciadas em locais de estágios.

0 grupo permaneceu em tarefa explícita, trabalhando conceitualmente, com alguns momentos de fuga do assunto abordado. Durante a discussão, relatou que realmente busca respostas prontas, na medida em que está acostumado com o modelo do ensino tradicional. Apesar de não obter essas respostas, referiu sentir-se acolhido.

Quanto aos vetores, observamos a afiliação, pertença, cooperação, pertinência, comunicação e aprendizagem.

No final do encontro, os alunos revelaram que, mesmo sendo um grupo de aprendizado, não deixou de ser terapêutico em algumas situações, apontando o alívio de ansiedades/ "válvula de escape".
Ao término desse grupo operativo, solicitamos aos alunos que fizessem uma avaliação dos encontros ocorridos. Eles referiram que seria interessante manter a atividade nos próximos anos, porém, como disciplina optativa, sugerindo oito encontros a serem realizados durante 0 período de estágio supervisionado.

Apesar de relatarem que a experiência foi proveitosa, sentiram a necessidade de obter respostas a algumas de suas inquietações, considerando que o coordenador é alguém mais experiente, que tem vivências a compartilhar.

\section{ANÁLISE GERAL}

Como observadores e coordenador do grupo operativo, consideramos que foi possível criar um espaço efetivo para a troca de experiências entre os discentes, favorecendo o enfrentamento do momento de transição para a vida profissional.

Concordamos com a sugestão dos alunos de manutenção da atividade como disciplina optativa. Talvez isso possa garantir um número maior de participantes, pois alguns discentes referiram que tinham dificuldade em negociar horário, em seu campo de estágio, para participar do grupo.

Cabe salientar que a opção por realizarmos os encontros, apesar do número restrito de integrantes, justifica-se pelo compromisso que assumimos com os alunos interessados.

Tendo em vista o objetivo deste grupo operativo, resolvemos utilizar como disparador temático, as atividades vivenciais que despertassem a sensibilidade dos alunos para o tema a ser abordado durante o grupo, facilitando a expressão verbal de seus pensamentos e sentimentos.

Um dos pontos que emergiu ao efetuarmos este trabalho refere-se à dificuldade de sermos coordenadores/observadores fundamentados na proposta Pichoniana e, ao mesmo tempo, exercermos o papel de professor "formal" dos participantes.

Uma dessas dificuldades é encontrarmos o "equilíbrio" entre a construção da aprendizagem pelo próprio grupo e a intervenção como "coordenador-docente" considerando, principalmente, que os alunos solicitam respostas prontas aos seus questionamentos e, nós, professores, muitas vezes, ainda sentimos a responsabilidade de "passar" conteúdos e experiências.

Outra dificuldade diz respeito ao enfrentamento pelo educador das críticas feitas pelos alunos em relação ao exercício profissional do enfermeiro: Qual o papel do enfermeiro na prática? Como se dá a articulação com os demais profissionais? Como conciliar os conteúdos teóricos com a prática?

Essas questões nos mobilizam a repensar sobre 0 ensino de enfermagem: 0 que estamos ensinando? Qual 
a nossa relação com a prática? Até que ponto esses questionamentos dos estudantes já estão banalizados em nosso fazer, visto que ao longo da formação nos deparamos com essas perguntas que revelam um cotidiano profissional fundamentado em condutas estereotipadas, pouco aberto para transformação?

Ao mesmo tempo que esses questionamentos permitem um olhar crítico sobre a formação, despertamnos resistências já que dizem respeito ao nosso fazer cotidiano: 0 que somos? 0 que fazemos? Quais os modelos que fundamentam o processo ensino-aprendizagem?

Há de se considerar que, para poder pensar, é preciso admitir e tolerar um certo nível de ansiedade, abrindo-se às possibilidades e perdendo estereotipias, ou seja, controles seguros e fixos. No medo de pensar está presente o temor de passar ansiedades, ficando nelas encerrado, sem poder sair ${ }^{15}$.

As dificuldades acima mencionadas refletem que a concepção tradicional do processo ensino-aprendizagem, ainda é predominante no contexto de nossa Escola.

Por concepção tradicional do processo ensino-aprendizagem, compreendemos o processo que, predominantemente, considera como importante a transmissão de conteúdos informativos de um "professor que sabe" para um "aluno que não sabe", desvinculados do contexto prático, dicotomizando o pensar-sentir-agir.

No contexto do sistema educativo tradicional, a sala de aula é descrita como local de poder do docente que coloca o aluno como um sujeito impotente e submisso, reproduzindo uma relação social de dominação, autoritária e hierárquica. Esse modelo de aprendizagem aceita o instituído como uma ordem natural e dissocia mente/ corpo, pensamento/ realidade, teoria/prática, trabalho manual/ intelectual, tarefa/ prazer $^{16}$.

Cabe considerar que a relação professor-aluno não se trata de uma forma antagônica entre vítima/agressor, já que o docente também está inserido nesse contexto hierárquico e rigidamente autoritário, sendo formado para mostrar o que sabe e exigir do discente o que aprendeu, em uma lógica do saber como repetição. Assim, ambos são alienados de sua necessidade e capacidade criativa e negados como pessoas pensantes ${ }^{16}$.

É necessário que professores e estudantes juntos percebam a necessidade de mudança e implementação do novo, socializando-se, incorporando valores, condutas que fazem parte do momento histórico-social no qual estão inseridos ${ }^{17}$.

A abordagem de grupo operativo propõe, por outro lado, outra concepção do processo ensino-aprendizagem, sendo necessário romper com o estereótipo de que o educador é aquele que "manda" e tem o papel de ensinar, enquanto o educando tem o papel de aprender. Na verdade, a aprendizagem envolve a relação professor-aluno na qual ensinar/aprender estão constantemente interligados ${ }^{6}$.

\section{CONSIDERAÇÕES FINAIS}

Consideramos que neste trabalho empreendido com os alunos de graduação em enfermagem foi possível, em muitos momentos, exercitar a possibilidade da "ensinagem"15. Ou seja, ao mesmo tempo que os alunos tiveram oportunidade de reelaborar suas próprias vivências no enfrentamento desse momento de transição para a vida profissional, nós, docentes, também estamos reelaborando nossas experiências relacionadas ao processo ensino-aprendizagem em enfermagem, buscando refletir acerca dos limites do modelo tradicional.

Nesse processo, enfrentamos às dificuldades em se implementar propostas que enfocam aluno e professor como pessoas que podem compartilhar experiências em um processo ensino-aprendizagem dinâmico que vai construindo-se nas relações interpessoais, políticas, enfim, humanas que vão se configurando em um dado contexto.

Cabe ressaltar que, em algumas das disciplinas da graduação, sob nossa responsabilidade, já procurávamos transcender ao ensino tradicional. Mas, essa transcendência exige um movimento contínuo de reelaboração das bases conceituais e vivenciais que fundamentam a nossa atividade docente para além das mudanças apenas de técnicas de ensino. A grande questão que se apresenta é o permanente processo reflexivo acerca de nossas concepções pedagógicas que estão articuladas à realidade social e à prática educativa.

Nesse sentido, o referencial Pichoniano vem abrindo a possibilidade desse constante repensar e, fundamentalmente, de refazer a prática do ensinar, ou melhor, de "ensinagem", incorporando alunos e docentes como sujeitos críticos e criativos que podem, coletivamente, transformar o cotidiano.

Cabe considerar que pensar em sujeitos críticos e criativos é uma das questões primordiais que vêm sendo enfocada atualmente na Enfermagem, tendo em vista as novas diretrizes curriculares propostas ${ }^{1}$. Assim, pensamos que essa abordagem pode ser mais uma possibilidade para a busca de transformações na prática do ensino em enfermagem. 


\section{Referências}

1.Grossi E. LDB: Lei de Diretrizes e Bases da Educação . Lei no 9 394/ 96. Rio de Janeiro (RJ): DP\&A; 1998.

2. Lapis BR. Relato de uma experiência de grupo operativo como mobilizador de pacientes psiquiátricos crônicos em uma unidade de internação hospitalar. [dissertação de mestrado].Porto Alegre (RS): Universidade Federal do Rio Grande do Sul; 1980.

3. Ciampone MHT. Grupo operativo: construindo as bases para o ensino e a prática na enfermagem. [tese de livre docência]. São Paulo (SP): Escola de Enfermagem /USP; 1998.

4.Cavalcante MBG. 0 grupo operativo como estratégia de assistência de enfermagem: a prática revelando caminhos para mudanças no cotidiano dos pacientes com transtorno mental [dissertação de mestrado]. São Paulo (SP): Escola de Enfermagem/ USP; 1999.

5. For tuna CM. 0 trabalho de equipe numa unidade básica de saúde: produzindo e reproduzindo-se em subjetividade: em busca do desejo, do devir e de singularidades. [dissertação de mestrado] Ribeirão Preto (SP): Escola de Enfermagem /USP; 1999.

6. Lucchese R. Grupo operativo como estratégia pedagógica em um curso de graduação em enfermagem: um espaço continente das vivências dos alunos quartanistas. [dissertação de mestrado]. São Paulo (SP): Escola de Enfermagem/USP; 2000.

7. Villela DVAL. 0 grupo operativo como estratégia para a assistência de enfermagem: mulheres em depressão [dissertação de mestrado]. São Paulo (SP): Escola de Enfermagem/USP; 2000.

8. Pichon-RivièreE. Oprocessogrupal. 6 a ed. SãoPaulo (SP):MartinsFontes;2000.

9. Gayotto MLC, Domingues I. Liderança: aprenda mudar em grupo. $4^{\mathrm{a}}$ ed. Petrópolis (RJ): Vozes; 1995.

10. Rosembom J. A dialética dos processos grupais. Buenos Aires (AR): Primera Escuela Privada de Psicología Social; 1983.

11. Pichon-Rivière E, Quiroga AP. Psicología da vida cotidiana. São Paulo (SP): Martins Fontes; 1998.

12. Racedo J. Teoria de los roles. Buenos Aires (AR): Primera Escuela Privada de Psicología Social; 1983.

13. Jasiner C. Cono invertido. Buenos Aires (AR): Primera Escuela Privada de Psicología Social; 1983.

14. Berstein M. Contribuições de Pichon-Rivière à pisicoterapia de grupo. In: Osório LC, organizador. Grupoterapia hoje. Porto Alegre (RS): Artes Médicas; 1989. p.108-31.

15. Bleger J.Temas de psicologia: entrevistas e grupos. São Paulo (SP): Martins Fontes; 2001.

16. Quiroga AP. Enfoques y perspectivas en psicología social: desarrollos a partir del pensamiento de Enrique Pichon Rivière. Buenos Aires (AR): Ed Cinco; 1986.

17. Mostardeiro SCTS. Refletindo sobre a formação do enfermeiro: a prática docente a partir do imaginário pedagógico. Esc Anna Nery Rev Enferm 2004 abr; 8 (1): 21-28.

\section{Sobre as Autoras}

Adriana Katia Corrêa

Professor Doutor do Departamento de Enfermagem Geral e Especializada da Escola de Enfermagem de Ribeirão Preto da Universidade de São Paulo. (EERP-USP)

\section{Maria Conceição B. de Mello e Souza}

Professor Doutor do Departamento de Enfermagem Psiquiátrica e Ciências Humanas da Escola de Enfermagem de Ribeirão Preto da Universidade de São Paulo. (EERP-USP)

\section{Toyoko Saeki}

Professor Doutor do Departamento de Enfermagem Psiquiátrica e Ciências Humanas da Escola de Enfermagem de Ribeirão Preto da Universidade de São Paulo. (EERP-USP) 


\section{ANEXO}

Pontos a serem observados numa crônica de grupo operativo

(Instituto de Psicologia Social Enrique Pichon-Rivière de Ribeirão Preto)

1. Situação de abertura: emergentes de abertura, ansiedades predominantes;

2. Situação de tarefa: o tipo de relação que aparece entre integrantes e o objeto de conhecimento. Como a temática é abordada? (vivencial ou conceitualmente). Ocorrem saltos de aprendizagem?;

3. Relação entre abertura e fechamento: visualizar obstáculos que aparecem e quais as formas de resolução;

4. Conflito central da reunião;

5. Papéis mais significativos nesses conflitos;

6. Porta-vozes que emergem e em que situação aparecem;

7. Quanto à temática: observar a relação entre "temas pessoais" e "temas grupais", por exemplo: fantasias inconscientes - fantasias individuais que têm ressonância em nível de grupo;

8. Tipo de comunicação: características e desenvolvimento;

9. Qual o vetor predominante da reunião?;

10. Características do vínculo grupo- coordenador;

11. Situar contexto político- social, se houver acontecido algum fato relevante. 